\title{
COVID-19 ASSOCIATED PSYCHOTIC DISORDER WITH SUICIDAL BEHAVIOUR - CASE REPORT
}

\author{
Tonka Borovina $^{1}$, Tonći Mastelić ${ }^{1}$, Gordana Glavina $^{2}$ \& Trpimir Glavina ${ }^{1}$ \\ ${ }^{I}$ Clinic for Psychiatry, University Hospital Centre Split, Croatia \\ ${ }^{2}$ Clinical Department of Diagnostic and Interventional Radiology, University Hospital Centre Split, Croatia
}

received: 29.3.2021;

revised: 6.5.2021;

accepted: 20.5.2021

\section{INTRODUCTION}

Severe acute respiratory syndrome coronavirus 2 (SARS-CoV-2), causing coronavirus disease 2019 (COVID-19), emerged in late 2019 (Jakovljević et al. 2020). Since the start of the COVID-19 pandemic, we are facing complex neuropsychiatric syndromes (Sinanović et al. 2020), including the first onset of COVID19-associated psychosis, a serious mental disorder primarily characterized by impaired reality testing. The aetiology of COVID-19-associated psychosis is still not clear and may be multifactorial, including psychosocial and organic factors (Haddad et al. 2020, Jakovljević et al. 2020).

This study aims to present the woman who developed psychotic symptoms with suicidal behaviour following a COVID-19 infection and briefly discuss possible mechanisms in light of relevant literature.

\section{CASE REPORT}

A 74-year-old woman with a past medical history of chronic obstructive pulmonary disease, osteoporosis and breast cancer was admitted in December 2020 at the Clinic of Psychiatry (University Hospital Centre, Split). Prior to arrival, she attempted suicide which was prevented by her family. The patient's family reported that she has become socially isolated, having a sleeping disturbance and stopped eating due to delusions that her food is poisoned following COVID19 infection which was around one month before admission to our Clinic. Symptoms at the time of diagnosis with COVID-19 were notable for a lowgrade fever, rhinorrhea, headache and fatigue. She hadn't any psychotic symptoms before nor she was hospitalised in the department of psychiatry.

During psychiatric assessment patient was feeling tense, she was trying to dissimulate but exhibited paranoid thinking. Her mood was dysphoric with reduced affect modulation. She denied having suicidal thoughts when asked by a psychiatrist. She also denied auditory or other sensory hallucination. Orientation, attention and concentration were intact on bedside testing. On physical examination, no acute findings were revealed.
Her blood tests showed microcytic anaemia with haemoglobin $113 \mathrm{~g} / \mathrm{L}$ (Ref: 119-157 g/L), MCV 80.7 fL (Ref: 83.0-97.2), MCH 25.6 pg (Ref: 27.4-33.9) and MCHC 317 g/L (Ref: 320-345), mildly elevated neutrophils with $73.5 \%$ (Ref: 44-72), mildly low lymphocytes $17 \%$ (Ref: 20-46), normal level of Creactive protein $(<5 \mathrm{mg} / \mathrm{L})$, together with normal liver and renal function.

Due to the patient's psychotic symptoms and years, a head computed tomography (CT) was performed and revealed cortical atrophy, periventricular and subcortical hypodensities that may be due to vascular encephalomalacia. The hypodense lesion in a size of 1 centimetre was revealed in the right temporooccipital area. Therefore, a brain magnetic resonance imaging (MRI) was performed (Figure 1). Age-inappropriate cortical atrophy was noted. A hyperintense signal on T2 and FLAIR sequences in subcortical frontal and parietal areas and periventricular frontal, parietal and occipital areas which are pointing to chronic vascular lesions were revealed. Furthermore, a hyperintense signal on $\mathrm{T} 2$ sequence was registered in the left parietal and right temporal periventricular space what may represent chronic lacunar postinfarction lesions.

Considering the totality of her symptoms and clinical presentation following a SARS CoV-2 infection with the neuroimaging findings a Psychotic disorder due to another medical condition according to the Diagnostic and Statistical Manual of Mental Disorders, fifth edition (DSM 5) criteria was diagnosed (APA 2013).

The patient was offered reassurance and support from our psychiatric team. She was commenced on risperidone $2 \mathrm{mg}$ once daily which was gradually increased to risperidone $6 \mathrm{mg} /$ day a few days later. Diazepam $15 \mathrm{mg} /$ day was also included in the next days. Risperidone was commenced to treat her psychotic symptoms and diazepam for anxiolysis.

Within the ten days of admission, the patient's symptoms began to improve: she wasn't experiencing paranoid thoughts and she endorsed improvement in mood symptoms and insomnia. Unfortunately, on the $12^{\text {th }}$ day of hospitalisation, the patient died suddenly and unexpectedly. The family refused a hospital autopsy of the deceased. 

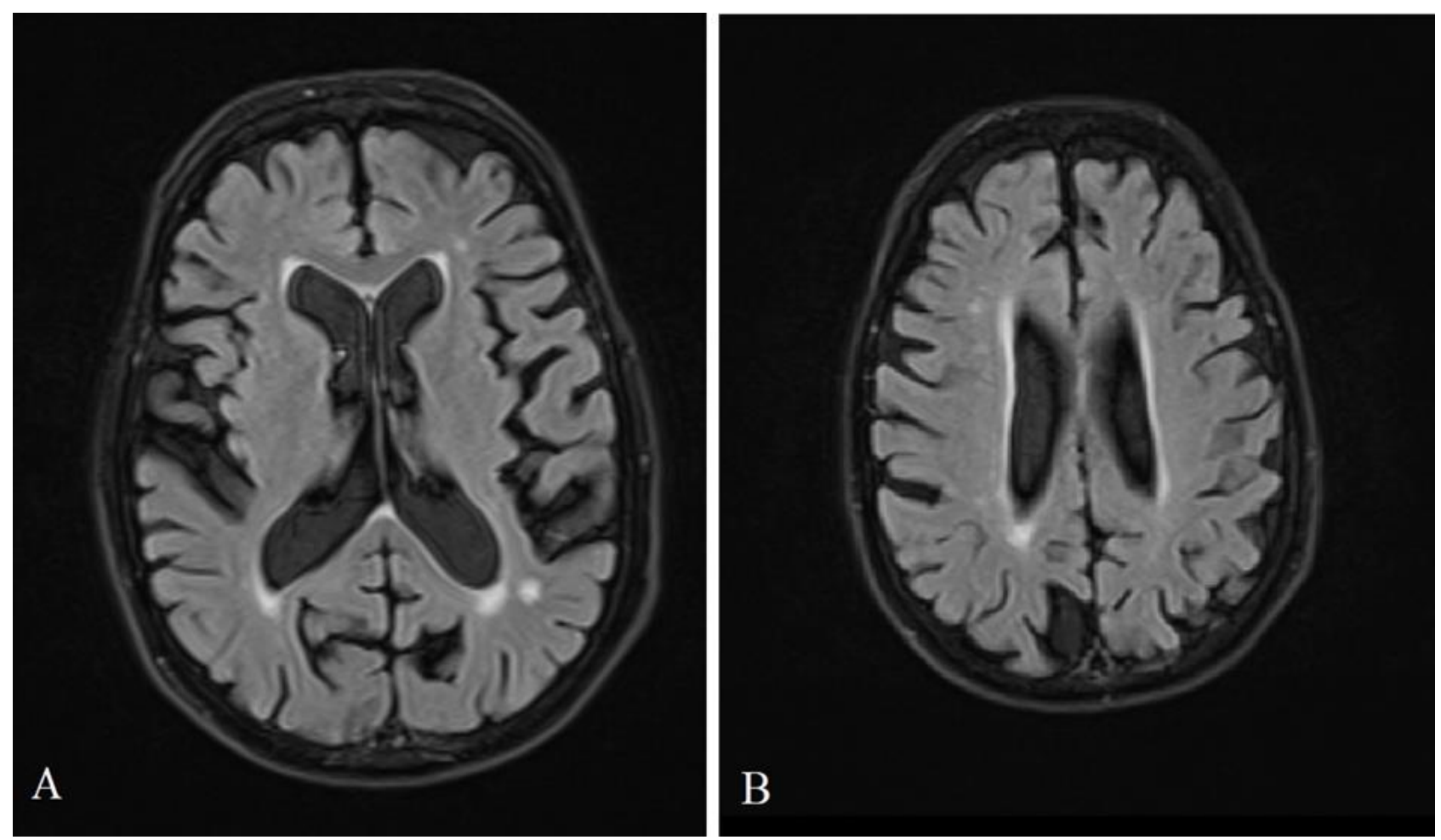

Figure 1. A transverse section of a FLAIR sequence of the patient's brain MRI. (A) Hyperintense (or high intensity) lesions left frontally and parietally and periventricular that may correspond to glial lesions of vascular aetiology. (B) High signal intensity punctiform lesions in the right frontal and parietal and periventricular lesions in terms of possible glial lesions of vascular aetiology

\section{DISCUSSION}

Psychosis is a serious mental disorder with impaired reality testing characterized primarily by delusions, hallucinations, disorganised thought, speech and behaviour (Gaebel \& Zielesek 2015). The aetiology of psychosis is complex and is still not fully understood but throughout the years there have been studies indicating an association between psychosis and infection, including coronavirus (Severance et al. 2011).

A novel coronavirus SARS CoV-2, causing COVID19 , rapidly enveloped in a global pandemic (Jakovljević et al. 2020). Although predominantly a respiratory illness, since the start of the pandemic we are facing complex neuropsychiatric sequelae of COVID-19 (Sinanović et al. 2020), including the first onset of psychosis. Evidence suggest 0.9 to $4 \%$ of individuals infected with SARS-CoV-2 develop psychotic spectrum disorders (Dinakaran et al. 2020). The involved mechanism is still unclear and may be due to a viral illness, treatment and increased psychosocial stress during pandemics (Haddad et al. 2020, Sinanović et al. 2020, Jakovljević et al. 2020). Reported cases of psychotic disorders associated with COVID-19 differ in the physical manifestation of COVID-19 infection (from asymptomatic to severe form), raising additional confusion in the overall problem with determining aetiology (Ferrando et al. 2020, Parra et al. 2020, Smith et al. 2020).
Here we present a case of COVID-19-associated psychotic disorder given the temporality between infection and psychiatric symptoms, atypical age of debut, quick recovery on antipsychotic treatment along with neuroimaging findings suggestible of COVID-19. Differential diagnoses were considered but excluded. Our patient's main psychotic symptoms were paranoid delusions which are in correlation with previous reports that implicate delusions as a dominant symptom in COVID-19-associated psychotic disorders (Thomas 2021, Ferrando et al. 2020, Smith et al. 2020). Suicidal behaviour seen in our patient adds to previous reports of psychotic symptoms and suicidality raising concern over the increased suicidal risk during the COVID-19 pandemic (Noone et al. 2020, Huarcaya-Victoria et al. 2020, Gillett \& Jordan 2020). Chronic vascular lesions and chronic lacunar postinfarction lesions revealed by patient's brain MRI could represent events more than 3 weeks old (Allen et al. 2012). As such, they could correlate with the onset of the symptoms in our patient and reflect an increased burden of microvascular i.e., cerebrovascular events among COVID-19 patients reported by others (Varatharaj et al. 2020). In one retrospective study of COVID-19 patients with psychotic symptoms, a patient with an acute ischemic event on a brain MRI scan was identified (Parra et al. 2020) while many case reports of psychosis associated with COVID-19 had normal CT/MRI brain scan (Ferrando et al. 2020, Smith et al. 2020, Majadas et al. 2020, Gilette et al. 
2020) or didn't make/present it at all (HuarcayaVictoria et al. 2020).

Valuable observation in our case is the accompanying occurrence of the psychotic disorder and the lacunar postinfarction lesions, as both psychiatric manifestations and ischemic events have been described as possible consequences of the inflammatory response associated with COVID-19 (Jasti et al. 2020). Cytokines have been related to the pathogenesis of psychosis, but psychosis can also be a manifestation of ischemic events that resulted from hypercoagulability and vascular endothelial dysfunction mediated by proinflammatory cytokines (Parra et al. 2020, Gavriilaki et al. 2020). Although our patient's symptoms of COVID-19 infection weren't severe, particularly proinflammatory cytokine elevation occurs in milder cases also (Watson et al. 2021). Interestingly, some studies implicate complement activation and hypercoagulation prior to psychosis in the general population (Mongan et al. 2020). These findings are still limited, yet coagulopathy may represent another potential mechanism by which COVID-19 mediated psychotic disorder in our case. Our patient's markers of inflammation and coagulation were not measured at the onset of her symptoms, and beside mildly elevated neutrophils and mildly lowered lymphocytes, they were normal at admission to our Clinic. Worth mentioning, absence of elevated blood C-reactive protein level have also been documented in studies associating inflammatory processes with psychosis and suicide (Noone et al. 2020).

Other proposed mechanism of COVID-19 associated neuropsychiatric manifestation in the literature includes the possibility of CNS invasion since other coronaviruses are known to be neurotropic and neuroinvasive (Raony et al. 2020, Sinanović et al. 2020). Moreover, the aetiology of the psychotic symptoms described here may have been also related to the uncovered or unarticulated stress of the COVID-19 pandemic (Haddad et al. 2020). However, the lack of COVID preoccupation in this patient, the fact that before admission she was living with her family which makes the impact of factors such as social isolation minimal, makes this option less likely.

Our patient showed almost complete resolution of her symptoms in 10 days of treatment with risperidone. This case adds to previous reports which have responded well to atypical antipsychotic treatments, i.e. risperidone (Majadas et al. 2020, Smith et al. 2020).

Despite our systematic approach, there may be some possible limitations in this study. One concerns the lack of pre-COVID-19 neuroimaging what limits our ability to make causal reasoning about the mechanism of MRI tissue abnormalities. Another concerns the patient's unexpected and sudden death that opens more questions about potential COVID-19 consequences as an autopsy was not made.

\section{CONCLUSION}

We report on the case of a 74-year-old woman who manifested psychotic symptoms and suicidal behaviour following a COVID-19 infection. We suggest this case may represent a manifestation of COVID-19 infection and discuss possible mechanisms in light of relevant literature. Still, further research is needed to elucidate the aetiology of COVID-19 associated psychosis, including coagulopathy associated with COVID-19 as one of the possible mechanisms. If the latter shows plausible, screening for coagulation abnormalities in psychotic disorder following even milder COVID-19 cases should be concerned.

\section{Acknowledgements: None.}

\section{Conflict of interest: None to declare.}

\section{Contribution of individual authors:}

Tonka Borovina bila je uključena u koncepciju i dizajn, prikupljanje podataka, pripremu rukopisa i pisanje rada.

Tonći Mastelić sudjelovao je u njezi bolesnika, prikupljanju podataka, recenziji nacrta rukopisa i pripremi rukopisa.

Gordana Glavina bila je uključena u brigu o pacijentima i prikupljanje podataka.

Trpimir Glavina sudjelovao je u njezi bolesnika, pripremi rukopisa i pregledao nacrt rukopisa.

\section{References}

1. Allen LM, Hasso AN, Handwerker $J \&$ Farid H: Sequence-specific MR imaging findings that are useful in dating ischemic stroke. Radiographics 2012; 32:1285-97; discussion 1297-9. doi:10.1148/rg.325115760. PMID: 22977018

2. American Psychiatric Association: Diagnostic and Statistical Manual of Mental Disorders, Fifth Edition (DSM-5). American Psychiatric Association, Arlington, VA, 2013

3. Dinakaran D, Manjunatha N, Naveen Kumar C\& Suresh BM: Neuropsychiatric aspects of COVID-19 pandemic: A selective review. Asian J Psychiatr. 2020 Oct;53:102188. doi: 10.1016/j.ajp.2020.102188. Epub 2020 May 30. PMID: 32512530; PMCID: PMC7261092

4. Ferrando SJ, Klepacz L, Lynch S, Tavakkoli M, Dornbush R, Baharani R et al.: COVID-19 Psychosis: A Potential New Neuropsychiatric Condition Triggered by Novel Coronavirus Infection and the Inflammatory Response? Psychosomatics 2020; 61:551-555.

doi: 10.1016/j.psym.2020.05.012. Epub 2020 May 19. PMID: 32593479; PMCID: PMC7236749

5. Gaebel $W \&$ Zielasek J: Focus on psychosis. Dialogues Clin Neurosci 2015; 17:9-18.

doi:10.31887/DCNS.2015.17.1/wgaebel. PMID:25987859; PMCID: PMC4421906 
6. Gavriilaki E, Anyfanti P, Gavriilaki M, Lazaridis A, Douma $S$ \& Gkaliagkousi E: Endothelial Dysfunction in COVID-19: Lessons Learned from Coronaviruses. Curr Hypertens Rep 2020; 22:63. doi:10.1007/s11906-02001078-6. PMID: 32852642; PMCID: PMC7449866

7. Gillett $G \&$ Jordan I: Severe psychiatric disturbance and attempted suicide in a patient with COVID-19 and no psychiatric history. BMJ Case Rep 2020; 3:e239191. doi: 10.1136/bcr-2020-239191. PMID: 33130587; PMCID: PMC7783370

8. Haddad PM, Al Abdulla M, Latoo J \& Iqbal Y: Brief psychotic disorder associated with quarantine and mild COVID-19. BMJ Case Rep 2020 Dec;16;13(12):e240088. doi: 10.1136/bcr-2020-240088. PMID: 33328211; PMCID: PMC7745456

9. Huarcaya-Victoria J, Meneses-Saco A \& Luna-Cuadros MA: Psychotic symptoms in COVID-19 infection: A case series from Lima, Peru. Psychiatry Res 2020; 293:113378. doi: 10.1016/j.psychres.2020.113378. Epub 2020 Aug 9. PMID: 32805590; PMCID: PMC7415343

10. Jakovljevic $M$, Bjedov $S$, Jaksic $N$ \& Jakovljevic $I$. COVID-19 Pandemia and Public and Global Mental Health from the Perspective of Global Health Securit. Psychiatr Danub. 2020; 32:6-14. doi:10.24869/psyd.2020.6. PMID: 32303023

11. Jasti M, Nalleballe K, Dandu V \& Onteddu S: A review of pathophysiology and neuropsychiatric manifestations of COVID-19. J Neurol 2020 Jun; 3:1-6. doi: 10.1007/s00415-020-09950-w. Epub ahead of print. PMID: 32494854; PMCID: PMC7268182.

12. Majadas S, Pérez J, Casado-Espada NM, Zambrana A, Bullón A \& Roncero C: Case with psychotic disorder as a clinical presentation of COVID-19. Psychiatry Clin Neurosci 2020 Oct;74(10):551-552. doi: 10.1111/pcn.13107. Epub 2020 Jul 31. PMID: 32639089; PMCID: PMC7361769

13. Mongan D, Cannon $M \&$ Cotter DR: COVID-19, hypercoagulation and what it could mean for patients with psychotic disorders. Brain Behav Immun 2020 Aug;88:910. doi: 10.1016/j.bbi.2020.05.067. Epub 2020 May 29. PMID: 32473945; PMCID: PMC7256555

14. Noone R, Cabassa JA, Gardner L, Schwartz B, Alpert JE \& Gabbay V: Letter to the Editor: New onset psychosis and mania following COVID-19 infection. J Psychiatr Res 2020; 130:177-179. doi:10.1016/j.jpsychires.2020.07.042.
Epub 2020 Aug 8. PMID: 32823051; PMCID: PMC7414775

15. Parra A, Juanes A, Losada CP, Álvarez-Sesmero $S$, Santana VD, Marti I et al.: Psychotic symptoms in COVID-19 patients. A retrospective descriptive study. Psychiatry Res 2020 Sep;291:113254. doi: 10.1016/j.psychres.2020.113254. Epub 2020 Jun 24. PMID: 32603930; PMCID: PMC7311337

16. Raony Í, de Figueiredo CS, Pandolfo P, Giestal-de-Araujo E, Oliveira-Silva Bomfim $P$ \& Savino W: PsychoNeuroendocrine-Immune Interactions in COVID-19: Potential Impacts on Mental Health. Front Immunol 2020 May 27;11:1170. doi: 10.3389/fimmu.2020.01170. PMID: 32574266; PMCID: PMC7267025

17. Severance EG, Dickerson FB, Viscidi RP, Bossis I, Stallings $C R$, Origoni AE et al.: Coronavirus immunoreactivity in individuals with a recent onset of psychotic symptoms. Schizophr Bull 2011 Jan;37(1):1017. doi: 10.1093/schbul/sbp052. Epub 2009 Jun 2. PMID: 19491313; PMCID: PMC3004184

18. Sinanović O, Muftić $M$ \& Sinanović S. COVID-19 Pandemia: Neuropsychiatric Comorbidity and Consequences. Psychiatr Danub 2020; 32:236-244. doi:10.24869/psyd.2020.236. PMID: 32796792

19. Smith CM, Komisar JR, Mourad A \& Kincaid BR: COVID-19-associated brief psychotic disorder. BMJ Case Rep 2020 Aug; 11;13(8):e236940. doi: 10.1136/bcr-2020236940. PMID: 32784244; PMCID: PMC7418683.

20. Thomas SP: Psychosis Related to COVID-19: Reports of a Disturbing New Complication. Issues Ment Health Nurs 2021; 42:111. doi: 10.1080/01612840.2021.1873054. PMID: 33528292.

21. Varatharaj A, Thomas N, Ellul MA, Davies NWS, Pollak TA, Tenorio EL et al.; CoroNerve Study Group. Neurological and neuropsychiatric complications of COVID-19 in 153 patients: a UK-wide surveillance study. Lancet Psychiatry 2020; 7:875-882. doi:10.1016/S22150366(20)30287-X. Epub 2020 Jun 25. Erratum in: Lancet Psychiatry. 2020 Jul 14;: PMID: 32593341; PMCID: PMC7316461

22. Watson CJ, Thomas RH, Solomon T, Michael BD, Nicholson TR \& Pollak TA: COVID-19 and psychosis risk: Real or delusional concern? Neurosci Lett 2021 Jan 10;741:135491. doi: 10.1016/j.neulet.2020.135491. Epub 2020 Nov 18. PMID: 33220366

Correspondence:

Tonka Borovina, MD

Clinic for Psychiatry, University Hospital Centre Split

Spinčićeva 1, 21000 Split, Croatia

E-mail: tborovina@gmail.com 